\title{
Gestur Siswa Sekolah Menengah Pertama dalam Memecahkan Masalah Matematis secara Berkelompok
}

\author{
Nur Laili Achadiyah ${ }^{1}$ \\ Sekolab Menengah Pertama Negeri 27 Kota Malang \\ e-mail: nurlailiachadiyah@gmail.com
}

\begin{abstract}
This research aimed to describe in detail the students' gesture in collaborative mathematical problems solving. The results showed that students gestured in solving mathematical problem collaboratively. The students' gesture is intended to (a) him/her self, (b) others, or (c) him/her self and others. According to the presence or absence of accompanying speech, the students' gesture may occur (a) before the speech, (b) in conjunction with speech, (c) after the speech, or (d) without speech. The functions of the students' gesture in collaborative mathematical problems solving are to (1) draw attention to the important aspects of the problem (2) show the position of something in the matter, (3) attract, focus, and keep attention on the important aspects that are being discussed, (4) write something that already exists in the mind as the final form, (5) concrete something that is being considered, and (6) guide or direct the process of thinking.
\end{abstract}

Keywords : collaborative, mathematical problem, problem solving, students' gesture.

\section{PENDAHULUAN}

Pemecahan masaah adalah inti pembelajaran matematika (Karatas \& Baki, 2013; Pimta, Tayruakham, \& Nuangchalerm, 2009). Cooney, Davis, \& Henderson (1975) menyatakan bahwa siswa akan lebih analitis untuk mengambil keputusan dalam kehidupan dengan pemecahan masalah matematis. Faktanya, kemampuan siswa dalam memecahkan masalah matematis masih rendah (Kaur \& Yap, 1999; Zanzali \& Nam, 2000). Fakta ini juga sesuai dengan pengalaman peneliti selama mengajar di sekolah menengah pertama.

Beberapa penelitian terkait penggunaan gestur siswa dalam memecahkan masalah matematis sudah banyak dilakukan (Alibali, dkk., 1999; Rasmussen, Stephan, \& Allen, 2004; Edwards, 2009; Radford, Edwards, \& Arzarello, 2009; dan Francaviglia \& Servidio, 2011). Secara lebih khusus, Goldin-Meadow dan koleganya (Church \& Goldin-Meadow, 1986; Alibali \& Goldin-Meadow, 1993; Goldin-Meadow, Alibali, \& Church, 1993; dan Goldin-Meadow \& Alibali, 1995) meneliti gestur dalam pemecahan masalah konservasi bilangan dan ekivalensi.

Gestur didefinisikan sebagai gerakan lengan dan tangan yang bersesuaian dengan keluarnya ucapan (McNeill, 1992). Selanjutnya McNeill (1992) mengkategorikan gestur menjadi empat kategori utama, yaitu gestur ikonik, metaforik, deiktik, dan beat. Alibali \& Nathan (2007) memodifikasi klasifikasi gestur yang dibuat McNeill (1992) menjadi tiga jenis, yaitu (1) gestur menunjuk (pointing gesture), (2) gestur representasional (representational gesture), dan (3) gestur menulis (writing gesture). Gestur menunjuk tidak lain adalah gestur deiktik pada klasifikasi McNeill. Gestur representasional mencakup gestur ikonik dan gestur metaforik (Alibali \& Nathan, 2011:5). Gestur menulis mirip subkategori gestur simbolik-ikonik yang diajukan Edwards (2005).

Francaviglia \& Servidio (2011) menunjukkan keterkaitan yang sangat kuat antara gestur dan pemecahan masalah. Gestur berperan sebagai fasilitator dalam menyelesaikan masalah matematis. 
Gestur dapat mengurangi usaha kognitif siswa ketika menghadapi masalah matematis (Cook \& Goldin-Meadow, 2006). Bahkan, gestur dapat memberikan informasi mengenai selesaian dan selesaian alternatif untuk masalah matematis yang dihadapi (Cartmill, Beilock, \& Goldin-Meadow, 2012).

Reynold \& Reeve (2002) meneliti penggunaan gestur siswa saat memecahkan masalah matematis secara berkelompok dan menyarankan perlunya penelitian untuk melihat (1) apakah ada perbedaan gestur yang digunakan oleh masing-masing siswa, (2) apakah gestur bergantung pada situasi, dan (3) apakah mungkin mengidentifikasi pola gestur yang digunakan siswa. Penelitian mengenai gestur siswa dalam penyelesaian masalah secara berkelompok masih baru sehingga penelitian lebih lanjut masih diperlukan (Reynolds \& Reeve, 2002). Mengacu pada saran Reynold dan Reeve ini, peneliti merasa perlu untuk meneliti lebih lanjut penggunaan gestur siswa sekolah menengah pertama dalam memecahkan masalah matematis secara berkelompok.

\section{METODE PENELITIAN}

Penelitian ini menggunakan pendekatan kualitatif dengan jenis penelitian deskriptifeksploratif. Penelitian ini bertujuan untuk menjelaskan penggunaan gestur oleh siswa selama proses memecahkan masalah matematis secara berkelompok. Klasifikasi gestur yang digunakan mengacu kepada klasifikasi Alibali \& Nathan (2007). Gestur yang diteliti adalah gestur siswa yang dilakukan selama diskusi menyelesaikan masalah matematika secara kelompok dan diklasifikasikan menjadi gestur menunjuk, gestur representasional, dan gestur menulis. Gestur menunjuk dan gestur representasional mengacu pada definisi Alibali \& Nathan (2007) sedangkan gestur menulis diperluas kepada semua kegiatan menulis yang dilakukan siswa baik menghasilkan bekas permanen maupun tidak.

Untuk mengungkap atau memperoleh gambaran tentang penggunaan gestur tersebut, peneliti berusaha melakukan pengamatan secara teliti dan hati-hati. Peneliti merekam semua kegiatan siswa selama memecahkan masalah menggunakan perekam audio-visual. Wawancara terhadap siswa juga dilakukan untuk mendapatkan penjelasan mendalam terkait gestur yang dilakukan. Masalah matematis disajikan dalam lembar tugas dan telah divalidasi oleh satu dosen matematika dan satu guru matematika.

Subjek penelitian ini adalah siswa kelas IX-1, IX-2, dan IX-3 SMP Negeri 27 Kota Malang. Siswa dibentuk dalam kelompok yang heterogen dalam segi kemampuan. Setiap kelompok terdiri atas dua siswa dan diminta untuk memecahkan masalah yang diberikan oleh peneliti.

Masalah yang diberikan kepada siswa diambil dari salah satu soal PISA (Programme for International Student Assessment). Alasannya Indonesia masih menempati posisi terendah (urutan 64 dari 65 negara) dalam PISA tahun 2012. Soal ini kemudian dimodifikasi dan disesuaikan dengan keadaan nyata yang pernah dialami siswa. Soal yang diberikan kepada siswa sebagai berikut.

\section{BIANGLALA}

Pada suatu tempat rekreasi terdapat suatu permainan yang bernama Bianglala seperti gambar berikut.

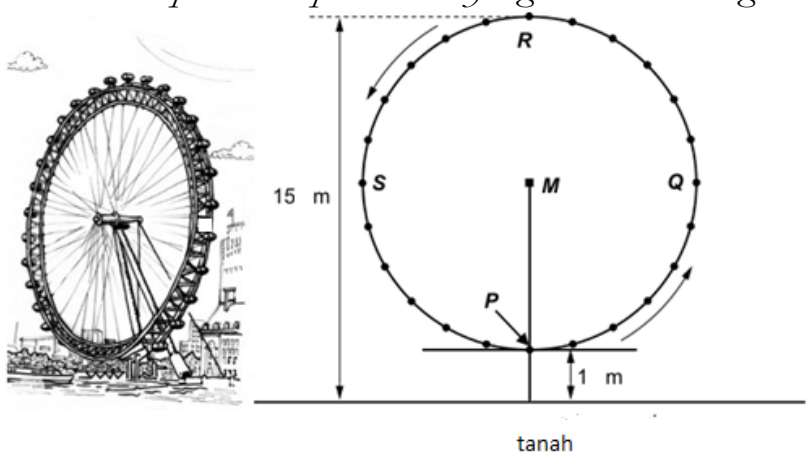

Gambar 1 Bianglala

Bianglala tersebut memiliki titik tertinggi 15 meter di atas permukaan tanah dan berputar berlawanan arah jarum jam seperti yang ditunjuk.kan oleb tanda panah. Titik. $M$ adalab titik pusat bianglala. Jika 
bianglala tersebut berputar dengan kecepatan konstan, maka untuk menempub satu putaran penub diperlukan waktu 40 menit. Andi naik bianglala mulai dari titik. P. Berapa panjang lintasan yang ditempuh Andi setelah 55 menit?

\section{HASIL DAN PEMBAHASAN}

\section{Jenis Gestur}

Data penelitian menunjukkan semua kelompok siswa yang diteliti melakukan gestur menunjuk, gestur representasional, dan gestur menulis saat memecahkan masalah matematis secara berkelompok. Gestur menunjuk merupakan gestur yang paling banyak digunakan oleh siswa. Fakta ini sesuai dengan hasil penelitian Alibali \& Nathan (2007), Alibali \& Nathan (2011:10), dan Özçaliskan \& Dimitrova (2013).

Gestur menunjuk yang dilakukan siswa sangat bervariasi, yaitu menggunakan ibu jari, jari telunjuk, jari tengah, atau menggunakan bolpen. Gestur menunjuk dengan jari telunjuk merupakan yang paling banyak dilakukan siswa. Adanya variasi gestur ini membuktikan dugaan Reynold \& Reeve (2002) bahwa ada perbedaan gestur yang digunakan oleh masing-masing siswa.

Data penelitian menunjukkan bahwa gestur menunjuk seringkali bersamaan dengan ucapan. Hal ini mendukung pernyataan Alibali \& Nathan (2011) bahwa gestur menunjuk sering digunakan bersamaan dengan ucapan. Meskipun demikian, data juga menunjukkan bahwa adakalanya gestur menunjuk dilakukan sebelum atau setelah ucapan. Hal ini mendukung pendapat Hostetter \& Alibali (2008:509) dan Alibali \& Nathan (2011) bahwa siswa dapat mengekspresikan konsep matematika dalam bentuk gestur sebelum mereka berkata.

Tujuan siswa (pembicara) melakukan gestur menunjuk juga bervariasi. Dalam penelitian ini diperoleh temuan bahwa gestur menunjuk dapat ditujukan untuk diri sendiri, siswa lain (pendengar), serta diri sendiri dan orang lain seperti terlihat pada Gambar 2. Gestur ini dilakukan dalam rangka memperoleh perhatian bersama atau mempertahankan perhatian bersama pada aspek penting dalam soal serta memperoleh gagasan baru untuk sampai pada selesaian (Reynolds \& Reeve, 2002).
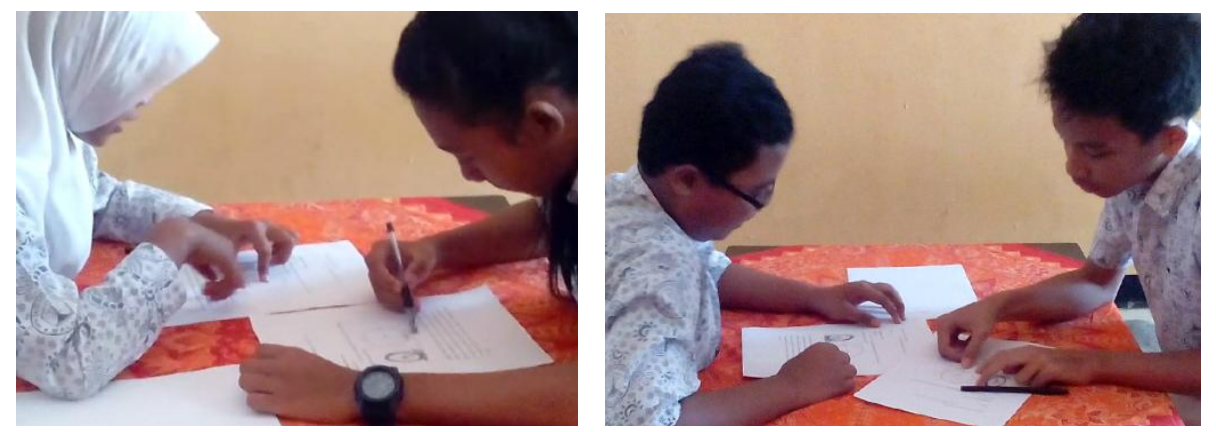

Gambar 2 Gestur Menunjuk (a) untuk Diri Sendiri dan (b) untuk Orang Lain

Gestur berikutnya yang banyak dilakukan siswa adalah gestur representasional. Gestur representasional dalam penelitian ini dapat dibedakan menjadi dua, yaitu (1) dilakukan pada gambar dan (2) dilakukan di udara. Gestur representasional yang dilakukan pada gambar misalnya gestur untuk menggambarkan diameter bianglala, arah putaran bianglala, satu putaran penuh (40 menit), putaran 10 menit, atau putaran 5 menit seperti terlihat pada Gambar 3.

Gestur representasional juga ada yang dilakukan di udara. Gestur representasional yang dilakukan di udara dilakukan oleh siswa dalam kelompok 1. Siswa menggambarkan lingkaran (bianglala) dengan kedua tangannya dan kemudian menggambarkan posisi diameter bianglala tersebut pada representasi lingkaran yang dibuat sebelumnya seperti terlihat pada Gambar 4. Fakta bahwa gestur representasional dapat dilakukan langsung pada objek dan dilakukan di udara sesuai dengan pendapat Alibali \& Nathan (2011). 

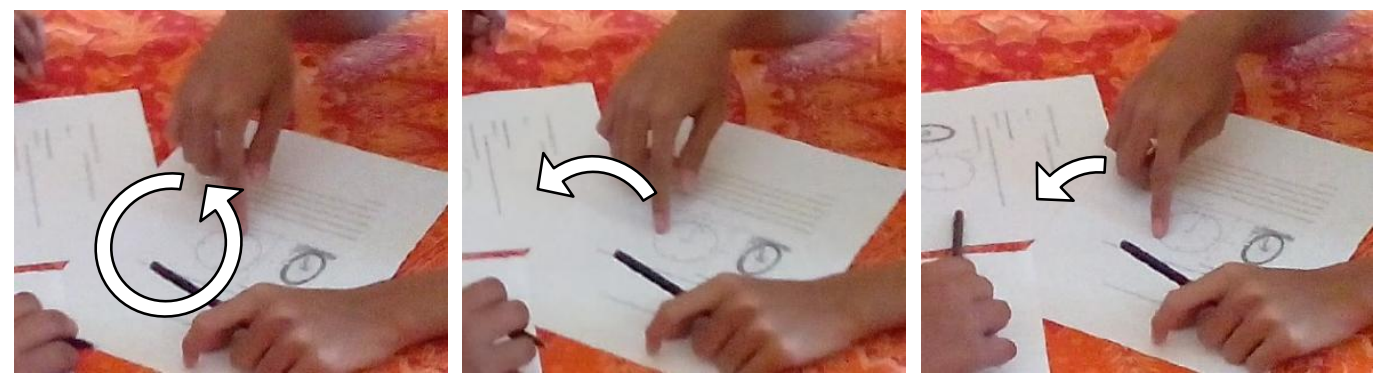

Gambar 3 Gestur Representasional pada Gambar

Gestur representasional yang dilakukan siswa dalam penelitian ini ada yang bersamaan dengan ucapan dan ada juga yang tanpa ucapan sama sekali. Hal ini sesuai pendapat Thompson (2014) bahwa gestur representasional dapat menyertai ucapan dan tanpa ucapan. Gestur representasional yang bersamaan dengan ucapan terjadi ketika siswa sedang memikirkan atau berusaha menjelaskan sesuatu baik untuk dirinya sendiri maupun orang lain. Dengan cara ini maka beban kognitif saat berpikir menjadi lebih ringan (Cartmill, Beilock, \& Goldin-Meadow, 2012) dan dapat berkontribusi dalam pemahaman pendengar (Alibali \& Nathan, 2011).

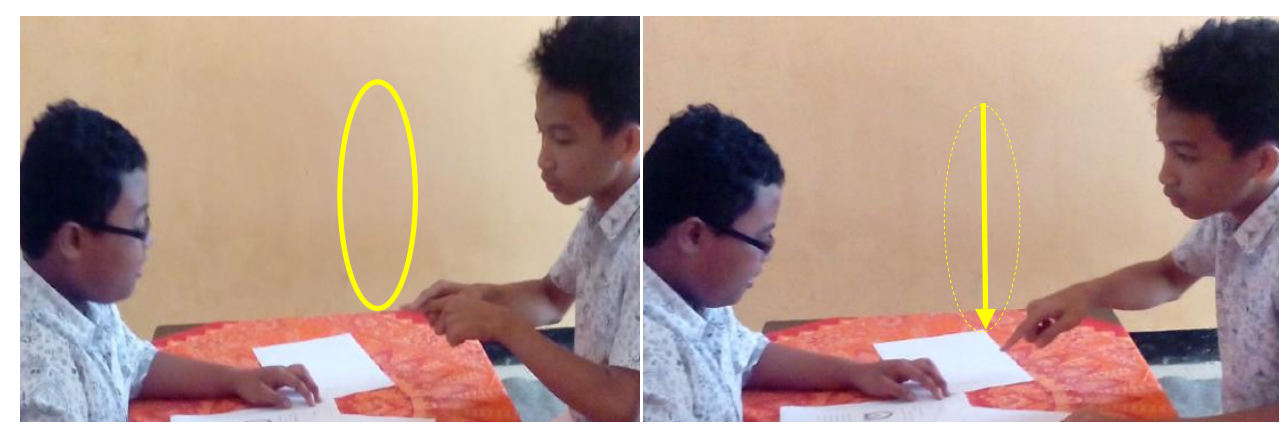

Gambar 4 Gestur Representasional di Udara

Gestur representasional yang tidak diiringi ucapan terjadi pada saat siswa memikirkan sesuatu lalu mengongkretkannya melalui gestur seperti pada Gambar 5. Hal ini mendukung pendapat Alibali \& Nathan, (2011) bahwa pembicara menggunakan gestur representasional ketika sedang berpikir. Jadi, gestur tidak hanya digunakan untuk menjelaskan ide tetapi juga mengekspresikan ide (Alibali \& Nathan, 2011) yang dapat terjadi tanpa ucapan sama sekali (Thompson, 2014).

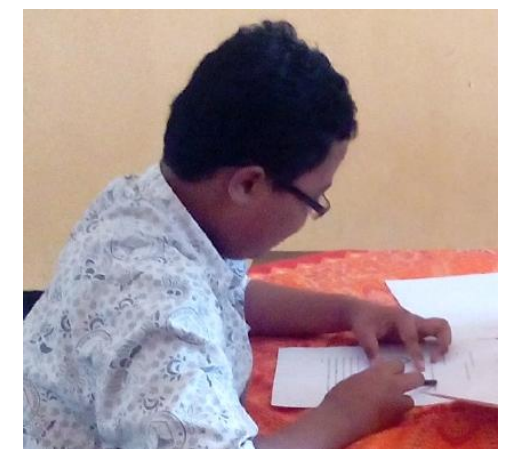

\section{Gambar 5 Gestur Representasional tanpa Ucapan}

Dilihat dari sudut pandang pembicara dan pendengar, gestur representasional yang dilakukan siswa dalam penelitian ini ditujukan pada pembicara sendiri, pendengar, serta pembicara dan pendengar. Gestur representasional yang dilakukan untuk pembicara sering kali tidak disertai ucapan. Gestur representasional yang dilakukan untuk pendengar saja atau untuk pendengar dan pembicara selalu disertai atau menyertai ucapan.

Gestur menulis dilakukan siswa dalam dua cara, yaitu menulis yang menimbulkan bekas permanen dan (2) menulis yang tidak menimbulkan bekas sama sekali. Dalam penelitian ini tidak 
ada gestur menulis yang dilakukan untuk menggambar sesuatu. Semua gestur menulis dalam penelitian ini dilakukan untuk menulis informasi, menulis hasil, atau menghitung.

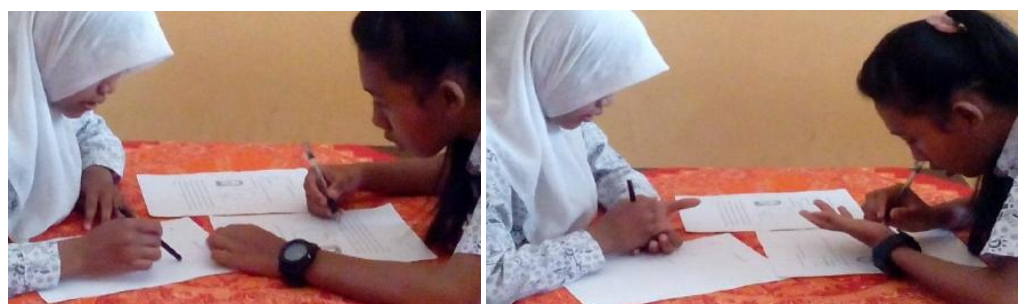

\section{Gambar 5 Gestur Menulis (a) Tanpa Bekas dan (b) Dengan Bekas di Tangan}

Gestur menulis ada yang disertai ucapan dan ada yang tanpa ucapan sama sekali. Gestur menulis yang disertai ucapan dilakukan ketika kegiatan menulis ini ditujukan untuk diri sendiri atau orang lain. Pada saat siswa menghitung untuk dirinya sendiri atau orang lain, misalnya menghitung keliling bianglala, ia melakukan gestur menulis sambil berbicara. Pada saat menulis yang diketahui atau menulis kesimpulan, ada yang disertai ucapan dan ada yang tidak disertai ucapan.

\section{Fungsi Gestur}

Ada fakta yang menarik mengenai tujuan penggunaan gestur yang dilakukan siswa dalam penelitian ini. Berdasarkan kegiatan wawancara terhadap subjek penelitian diperoleh data bahwa siswa kadang kala tidak mengetahui mengapa ia melakukan gestur. Gestur yang dilakukan siswa bersifat spontan mengiringi ucapan atau pikiran. Hal ini sesuai pendapat Vasc \& Ionescu (2013) dan Edwards (2009) bahwa gestur terjadi secara spontan.

Gestur menunjuk yang digunakan siswa dalam penelitian ini adalah untuk mengarahkan perhatian pendengar pada sesuatu dan menunjukkan posisi sesuatu. Hasill ini sesuai dengan klasifikasi Clark (2003). Gestur menunjuk berguna untuk mengarahkan perhatian pendengar pada referensi yang diinginkan pembicara (Marlsen-Wilson, Levy, \& Tyler, 1982). Ketika perhatian pendengar dan pembicara terpusat pada objek yang sama, maka hal ini akan menfasilitasi penemuan selesaian permasalahan yang dihadapi (Hanna \& Tanenhaus, 2004).

Hasil wawancara menghasilkan data bahwa gestur menunjuk dilakukan siswa untuk lebih memusatkan perhatian pada aspek penting dalam soal dan mempermudah memahami masalah. Hal ini mendukung pendapat Alibali \& Nathan (2011) bahwa gestur menunjuk yang mengarahkan ucapan pada objek dalam lingkungan belajar sangat bermanfaat dalam menyampaikan saling keterkaitan antara ide-ide matematis.

Gestur representasional yang dilakukan siswa dalam penelitian ini adalah untuk untuk menggambarkan objek nyata yang memuat ide matematika (bianglala), objek matematika (lingkaran), serta tindakan pada objek nyata (putaran bianglala) dan tindakan pada objek matematika (putaran pada gambar lingkaran). Alibali \& Nathan (2011) menyatakan bahwa gestur representasional sering muncul untuk menyimulasikan aksi pada objek matematika, menyimulasikan persepsi khususnya pada persepsi visual, dan menyimulasikan objek nyata. Siswa melakukan gestur representasional yang menyimulasikan aksi (putaran) dan persepsi (bayangan mental bianglala) saat berpikir mengenai masalah matematis yang dihadapi.

Fungsi komunikasi gestur representasional yang dilakukan siswa dalam penelitian ini adalah untuk mendapatkan perhatian sekaligus untuk menfokuskan perhatian. Siswa menarik perhatian teman diskusinya dan perhatiannya sendiri dengan melakukan gestur representasional. Hal ini mendukung hasil penelitian Reynolds \& Reeve (2002) bahwa gestur membantu siswa untuk memperoleh atau memusatkan perhatian bersama pada masalah.

Fungsi gestur representasional lainnya yang ditunjukkan siswa dalam penelitian ini adalah untuk mempertegas ucapan yang disampaikan. Hal sesuai dengan pendapat Vasc \& Ionescu (2013) dan McNeill (2005) bahwa gestur mempunyai dua peran dasar yaitu menyampaikan makna dan menjadi penjelas ucapan yang disampaikan. Penegasan ini dilakukan dengan membuat 
representasi. Sebagai contoh, siswa melakukan gestur representasional untuk menggambarkan diameter saat berpikir mengenai diameter. Gestur representasional memberikan bayangan konkret pada ekspresi atau komunikasi dari bersifat abstrak (Studdert-Kennedy, 1993 dan Radford, 2005).

Pada saat siswa mengalami kebuntuan dalam berpikir secara abstrak, kecenderungan siswa melakukan gestur representasional semakin besar. Siswa membuat representasi yang lebih konkret dari ide atau objek matematika yang dipikirkan. Jadi, gestur representasional berperan sebagai jembatan antara bayangan mental dan ide-ide abstrak matematis yang bersifat simbol dan formal (Arzaleno \& Edwards, 2005; Bazzini, 2001; Garber \& Goldin-Meadow, 2002; dan Kita, 2000). Dengan cara melakukan gestur representasional maka beban berpikir siswa akan semakin ringan dalam menyelesaikan masalah matematis (Kongthip, dkk., 2012; Cook \& Goldin-Meadow, 2006; Goldin-Meadow, dkk., 2001; Gallese \& Lakoff, 2005; dan Nemirovsky \& Ferrara, 2009).

Fungsi kognisi gestur menulis yang dilakukan siswa dalam penelitian ini dapat dibedakan menjadi tiga. Pertama, menuliskan atau mengongkretkan sesuatu yang sudah ada dalam pikiran sebagai bentuk final, misalnya menulis yang diketahui atau kesimpulan. Kedua, mengongkretkan sesuatu yang sedang dipikirkan, misalnya menulis sesuatu yang sedang dihitung. Ketiga menuntun atau mengarahkan proses berpikir, misalnya mengetahui langkah selanjutnya setelah melihat langkah sebelumnya saat menghitung.

Gestur menulis juga berfungsi sebagai alat komunikasi. Tulisan yang dihasilkan secara permanen merupakan hasil gestur menulis. Tulisan ini tidak lain adalah pesan yang ingin disampakan pada pembaca dalam hal ini teman diskusi atau guru. Gestur menulis juga berfungsi untuk menjelaskan sesuatu. Seperti yang terjadi dalam kelompok 3, seorang siswa melakukan gestur menulis untuk menjelaskan cara menghitung keliling dengan menggunakan $\pi=22 / 7$.

\section{PENUTUP}

Berdasarkan hasil penelitian ini dapat disimpulkan bahwa siswa menggunakan gestur menunjuk, gestur representasional, dan gestur menulis dalam menyelesaikan masalah matematis secara berkelompok. Gestur ditujukan untuk (a) diri sendiri, (b) orang lain, atau (c) diri sendiri dan orang lain. Dilihat dari ada atau tidak adanya ucapan yang menyertai, maka dapat disimpulkan bahwa gestur dapat terjadi (a) sebelum ucapan, (b) bersamaan dengan ucapan, (c) setelah ucapan, dan (d) tanpa ucapan.

Fungsi gestur yang dilakukan siswa dalam menyelesaikan masalah matematis secara berkelompok antara lain untuk (1) mengarahkan perhatian pada aspek penting dalam masalah (2) menunjukkan posisi sesuatu dalam masalah, (3) menarik, memusatkan, dan mempertahankan perhatian pada aspek penting yang sedang dibicarakan, (4) menuliskan sesuatu yang sudah ada dalam pikiran sebagai bentuk final, (5) mengongkritkan sesuatu yang sedang dipikirkan, serta (6) menuntun atau mengarahkan proses berpikir.

Dari hasil penelitian ini maka disarankan kepada guru untuk menggunakan gestur ketika menjelaskan materi matematika dan menganjurkan siswa menggunakan gestur ketika memecahkan masalah matematis. Penelitian lanjutan terkait penggunaan gestur dalam memecahkan masalah matematis secara berkelompok dapat dilakukan untuk melihat adakah perbedaan beban kognitif antara kelompok yang diperbolehkan menggunakan gestur dan kelompok yang tidak diperbolehkan menggunakan gestur selama menyelesaikan masalah. 


\section{DAFTAR RUJUKAN}

Alibali, M.W., Bassok, M., Solomon, K.O.S., Syc, E., \& Goldin-Meadow, S. (1999). Illuminating Mental Representations Through Speech and Gesture. Psychological Science, 10, 327-333.

Alibali, M.W. \& Goldin-Meadow, S. (1993). Gestur-speech Mismatch and Mechanisms of Learning: What the Hands Reveal about a Child's State of Mind. Cognitive Psychology, 25, 468-523.

Alibali, M. W. \& Nathan, M. J. (2007). Teachers' Gestures as a Means Scaffolding Student's Understanding: Evidence from an Early Algebra Lesson. In R. Goldman, R. Pea, B. Barron \& S. J. Derry (Eds), Video Research in the Learning Sciences, Mahwa, NJ: Erlbaum.

Alibali, M.W. \& Nathan, M.J. (2011). Embodiment in Mathematics Teaching and Learning: Evidence from Learner's and Teahcer's Gestures. The Journal of The Learning Sciences. DOI:10.1080/10508406.2011.611446, 1-40

Arzarello, F. \& Edwards, L. (2005). Gesture and The Construction of Mathematical Meaning. Dalam Chick, H. L. \& Vincent, J. L. (Eds.). Proceedings of the 29 Conference of the International Group for the Psychology of Mathematics Education, 1, 123-154. Melbourne: PME.

Bazzini, L. (2001). From Grounding Metaphors to Technological Devices: A Call for Legitimacy in School Mathematics. Educational Studies in Mathematics, 47, 259-271.

Cartmill, E.A., Beilock, S. \& Goldin-Meadow, S. (2012). A Word in The Hand: Action, Gesture and Mental Representation in Humans and Non-Human Primates. Philosophical Transaction of The Royal Society B. 367, 129-143.

Church, R.B. \& Goldin-Meadow, S. (1986). The Mismatch Between Gesture and Speech as an Index of Transitional Knowledge. Cognition, 23, 43-71.

Clark, H.H. (2003). Pointing and Placing. Dalam Kita, S (Ed.). Pointing. Where Language, Culture, and Cognition Meet (Halaman 243-268). Hillsdale NJ: Erlbaum.

Cook, S.W., \& Goldin-Meadow, S. (2006). The Role of Gesture in Learning: Do Children Use Their Hands to Change Their Minds? Journal of Cognition and Development, 7, 211-232.

Cooney, T.J., Davis, E.J., \& Henderson, K.B. (1975). Dynamics of Teaching Secondary School Mathematics. Boston : Houghton Mifflin Company.

Edwards, L. (2005). The Role of Gestures in Mathematical Discourse, Remembering and Problem Solving. Dalam Chick, H. L. \& Vincent, J. L. (Eds.). Proceedings of the 29 Conference of the International Group for the Psychology of Mathematics Education, 1, 123-154. Melbourne: PME.

Edwards, L. (2009). Gesture: Conceptual Integration and Mathematical Talk. International Journal for Studies in Mathematics Education, 1(1): 33-46.

Francaviglia, M. \& Servidio, R. (2011). Gesture as a Cognitive Support to Solve Mathematical Problems. Psychology, 2(2), 91-97.

Garber, P. \& Goldin-Meadow, S. (2002). Gesture Offers Insight into Problem-Solving in Adults and Children. Cognitive Science. 26, 817-831.

Gallese, V. \& Lakoff, G. (2005). The Brain's Concepts: The Role of the Sensory-motor System in Conceptual Knowledge. Cognitive Neuropsychology, 22, 455-479.

Goldin-Meadow, S. \& Alibali, M.W. (1995). Mechanisms of Transfer: Learning with a Helping Hand. Psychology of Learning and Motivation, 33, 115-157.

Goldin-Meadow, S., Alibali, M.W. \& Church, R. B. (1993). Transitions in Concept Acquisition: Using the Hand to Read the Mind. Psychological Review, 100, 279-297.

Goldin-Meadow, S., Nusbaum, H., Kelly, S.D., \& Wagner, S. (2001). Explaining Math: Gesturing Lightens the Load. Psychological Science, 12, 516-522.

Hanna, J.E., \& Tanenhaus, M.K. (2004). Pragmatic Effects on Reference Resolution in a Collaborative Task: Evidence from Eye Movements. Cognitive Science, 28, 105-115.

Hostetter, A.B. \& Alibali, M.W. (2008). Visible Embodiment: Gestures as Simulated Action. Psychonomic Bulletin \& Review. 15(3), 495-514 
Kaur, B. \& Yap, S.F. (1999). TIMSS: The Strength and Weaknesses of Singapore's Lower Secondary Pupils Performance in Mathematics. Dalam Waas, M. (Ed.). Enhancing Learning: Challenge of IntegratingThinking and Information Technology into the Curriculum (Halaman 436-444). Singapore: Educational Research Association.

Karatas, I \& Baki, A. (2013). The Effect of Learning Environment Based on Problem Solving on Students' Achievement of Problem Solving. International Electronic Journal of Elementary Education, 5(3), 249-268.

Kita, S. (2000). How Representational Gesturs Help Speaking. Dalam McNeill, D (Ed.), Language and Gestur (Halaman 162-185). Cambridge: Cambridge University Press.

Kongthip, Y., Inprasitha, M., Pattanajak, A. \& Inprasitha, N. (2012). Mathematical Communication by $5^{\text {th }}$ Grade Students' Gestures in Lesson Study and Open Approach Context. Psychology. 3(8), 632-637.

Marslen-Wilson, W., Levy, E., \& Tyler, L.K. (1982). Producing Interpretable Discourse: The Establishment and Maintenance of Reference. Dalam Jarvella, R.J. \& Klein, W (Eds.). Speech, Place and Action. Studies in Deixis and Related Topics (Halaman 339-378). Chichester: John Wiley.

McNeill, D. (1992). Hand and Mind: What Gesture Reveal about Thought. Chicago: Chicago University Press.

McNeill, D. (2005). Gesture and Thought. Chicago: University of Chicago Press.

Nemirovsky, R., \& Ferrara, F. (2009). Mathematical Imagination and Embodied Cognition. Educational Studies in Mathematics, 70, 159-174.

Özçaliskan, S. \& Dimitrova, N. (2013). How Gesture Input Provides a Helping Hand to Language Development. Seminars in Speech and Language, 34(4), 227-236.

Pimta, S., Tayruakham, S. \& Nuangchalerm, P. (2009). Factors Influencing Mathematic ProblemSolving Ability of Sixth Grade Students. Journal of Social Sciences, 5(4), 381-385.

Radford, L. (2005). Why Do Gesturs Matter? Gestures as Semiotic Means of Objectification. Dalam Chick, H. L. \& Vincent, J. L. (Eds.). Proceedings of the 29 Conference of the International Group for the Psychology of Mathematics Education, 1: 123-154. Melbourne: PME.

Radford, L., Edwards, L., \& Arzarello, F. (2009). Introduction: Beyond Words. Educational Studies in Mathematics, 70, 91-95.

Rasmussen, C., Stephan, M., \& Allen, K. (2004). Classroom Mathematical Practices and Gesturing. Journal of Mathematical Behavior, 23, 301-323.

Reynold, F.J. \& Reeve, R.A. (2002). Gesture in Collaborative Mathematics Problem-solving. Journal of Mathematical Behavior, 20, 447-460.

Studdert-Kennedy, M. (1993). A Review of Hand and Mind: What Gestures Reveal About Thought. Haskins Laboratories Status Report on Speech Research. SR-115/116,149-153.

Thompson, J.M. (2014). Teachers' Perceptions of Other Teachers' Spontaneous Hand Gesturing in The EFL Classroom. Novitas-ROY AL (Research on Youth and Language), 8(2), 119-135.

Vasc, D. \& Ionescu, T. (2013). Embodying Cognition: Gestures and Their Role in the Development of Thinking. Cognitie, Creier, Comportament, 17(2), 1-5

Zanzali, NAH \& Nam, L.L. (2000). Evaluating the Levels of Problem Solving Abilities in Mathematics. Dalam Alan, R. (ed.). Proceedings of the International Conference on Mathematics Education into the $21^{\text {st }}$ Century: Mathematics for living, Nov. 18 - 23, 2000. Amman, Jordan. 